with acre upon acre of its own wasted débris. On the crests of the heights the rock was found to be split by frosts along its joints ; numberless blocks had fallen off, and the slopes below were thickly strewn with them. On smoother declivities, such as those that descend from the lonely and barren Beinn Bharrain, each casual torrent was seen to have ploughed out of the loosened and corroded granite a deep trench, which in time might get widened and deepened into a lateral valley. The waste of mountains could not be more eloquently revealed. As the party in long file threaded its way through these solitudes, a feeling which had been growing all day found at last expression, and as the scattered scouts who, in the exuberance of young life, had dispersed up and down hill on either side of the main body, gathered together into one merry company at the edge of the dark and lonely Corrie au Lachan, it was unanimously agreed that had this band of stone-breakers seen nothing more than these proofs of how a mountain may be sculptured, the lesson was worth all the trouble and fatigue of the excursion.

\section{NÖE'S THERMO-ELECTRIC BATTERY}

$\triangle$ SUPPLY of dynamic electricity is almost as requisite now for the lecture table as the supply of gas or water. The decomposition of water and various other liquids, the decomposition of certain gases in Hoffmann's U tube, with the aid of Rhumkorff's coil, and the physical test afforded by the passage of electricity through vacua containing traces of different gases, are most constant lecture experiments. And no wonder: the brilliant purple light afforded by the passage of electricity through a nitrogen vacuum, is, perhaps, the best and most reliable, if, indeed, it be not the only, test for nitrogen gas ; while the decomposition of water gas, of ammonia, and of marsh gas, are experiments of the utmost importance in modern Chemistry. Hitherto the chief drawback has been the voltaic battery ; the setting up of the battery before the lecture, the taking it to pieces afterwards, the constant amalgamation of the zinc plates, the consumption of zinc and acid, the fumes-in a word, the general inconvenience inseparable from any form of voltaic battery, but reduced to a minimum in Sir William Thomson's constant gravitation battery. The former of these inconveniences are more apparent, when, as is often the case, the battery is only required for five minutes during the whole lecture.

Hence, when a statement recently appeared in Poggendorff's "Annalen," to the effect that a thermo-electric battery of great power had recently been constructed in Vienna by Franz Noë, we were glad to take the first opportunity of trying to what extent it could replace the ordinary voltaic battery for the lecture table. It was stated that the battery could readily decompose water, work a Rhumkorff's coil, and powerfully excite electro-magnets. As we understand from the maker that the battery about to be described is the only one in use in this country, it may be of interest to give a short account of its capabilities.

The battery consists of eighty elements, which are heated by eighty small Bunsen burners, the cooling of the opposite extremities being effected by broad, blackened sheets of copper, which of course radiate freely. The negative metal is a silver-white alloy drawn into wire, and partially enclosed in small copper cylinders to protect it from the direct action of the flame. The positive metal is a dull grey alloy extremely crystalline and brittle, and is cast into cylinders abont $20 \mathrm{~mm}$. long by $7 \mathrm{~mm}$. diameter. The composition of both these alloys is kept secret. Alternate pairs are separated by small square plates of mica. The elements can with readiness be combined either for quantity or intensity. Thus the eighty elements may be used together in one series, or in two series of forty elements, or in four serics of twenty elements.
The battery under consideration differs somewhat from that described in Poggendorff; it is larger; a sliding double groove keeps the burners in one position, exactly midway between the double rows of elements; and arrangements have been introduced in order to prevent radiation from the sides of the flames to the blackened copper radiators, that is, to the cool end of the elements.

According to the maker, the battery is equal to " 8 grosse Daniell'sche Elemente." The electromotive force of one element, according to $M$. Von Waltenhofen, was found to be equal to I'24 to I'36 Jacobi-Siemens's unit, while a Daniell's cell (no dimensions given) is equal to twelve of these units. One Noë's elements is said to be equal to II of the ordinary bismuth-antimony elements.

On testing the battery of eighty elements, we found it to be somewhat weaker than we expected. It is, however, very difficult to know to what extent the elements may be safely heated. No definite directions are given on the subject by the maker, and as the composition of the alloys is kept secret, one is unable to ascertain their fusing point without sacrificing a pair of elements.

With large iron electrodes placed in a solution of very dilute potash, water was decomposed by the battery at the rate of 22 cub. centimetres per minute. With small platinum electrodes exposing less than one square centimetre of surface in water rendered acid by dilute sulphuric acid, Io cc. of the mixed gases were evolved per minute. One of Graiffe's induction coils, capable of giving a spark $15 \mathrm{~mm}$. long, was connected with the battery. A copious stream of sparks I I $\mathrm{mm}$. long was produced. With a small 6-inch electro-magnet, surrounded by only two coils of wire, the battery produced a portative force of more than 20 lbs., when the gas was turned down so as to be nearly level with the orifice of the burners, and the flame was distant some $9 \mathrm{~mm}$. from the surface of the elements. It is very possible that the battery might be heated to a higher temperature than that employed for decomposing water without detriment. In no case did the upper cylin. ders glow with even a faint red heat.

Here then we have an instrument which at a moment's notice can be set in action, which consumes a small amount of gas, is tolerably portable, and which is suffi. cient for all ordinary electro-magnetic experiments, for lecture demonstration of the decomposition of water, ammonia, \&c., and for many purposes for which a voltaic battery has now to be used. Four or six of these batteries would be sufficient for all purposes save the electric light ; they might be made more compact, and could with ease be placed beneath and at one end of the lecture table. The lighting of a row of gas jets would thus furnish us at any moment with an abundant current of electricity. The battery is, indeed, less strong than one could wish, but the production of it is a step in the right direction; and we look forward to the time when powerful and compact thermo-electric batteries will be found in every lectureroom, and when the lighting of a row of gas jets will, through the medium of such batteries, furnish us at any moment with a powerful electric light.

We are at the outset of invention in this direction; several improvements in Noë's battery seem to us to be both advisable and practicable. Let the elements be enlarged, the brittle cylinders of alloy protected, the radiation of heat from the sides of the row of gas jets to the cool ends of the elements entirely prevented, which is by no means the case now ; and, if possible, let a current of cold water flow through pipes interspersed among the cooling plates. Again, let the pressure and amount of gas be indicated, and let the stop-cock admitting the gas be furnished with a projecting pin, moving on a graduated dial, so that any desired amount of gas (pre-determined) can at any time be caused to issue from the burners, and thus any desired strength of current (pre-determined in reference to the heating effect by ordinary electrometrical means) be obtained.
G. F. RODWELI 